\title{
Tail, paw and pup retrieving in the rat
}

W. E. WILSONCROFT AND D. V. SHUPE

CLAREMONT GRADUATE SCHOOL

\begin{abstract}
Over $80 \%$ of the mother rats in this study retrieved their own appendages (i.e. tails and paws), as well as their pups, during the first five post partum days. Such behaviors should not be considered abnormal although this is implied in some of the literature.
\end{abstract}

Mother rats normally retrieve their pups when they become scattered from the nest; they also retrieve foster pups from other litters (Beach \& Jaynes, 1956) and even pups from different species (Wiesner \& Sheard, 1933). Scattered reports have mentioned briefly that appendages (i.e. tails and paws) are also retrieved (Fisher, 1956; Eibl-Eibesfeldt, 1961; Slotnick, 1963; Wilsoncroft, 1963) but no quantification has heretofore been presented.

In the present study 35 Simonsen females, nulliparous, were mated and observed on retrieving tests ( $E$ scattered pups and recorded Ss responses for $15 \mathrm{~min}$.) on the first five days post partum. Ss were housed individually in observation cages ( $3 \mathrm{ft}$ by $1-1 / 2 \mathrm{ft}$ ) each of which contained a 6 in square black nesting box. The floor space was partitioned into 17 areas by lines painted on the floor. A constant litter size of six pups per litter was maintained throughout the experiment.

Analysis of variance confirmed the expected improvement in retrieving (e.g. decreased latencies until the first pup was picked up etc.) over the five testing days. Of particular interest in this study was the tail and paw retrieving. After gathering pups on the retrieving tests, and sometimes in the midst of this activity, Ss would grab their tails in their teeth and carry their appendage into the nest box. This behavior was directed toward the nest box, which distinguishes it from the "whirlingdance" often seen in simple tail chasing behaviors. After grasping their tails, these Ss would literally drag themselves across the observation cage to deposit their appendage in the next box and then emerge to repeat the performance time after time. Furthermore, Ss were observed to grab one of their anterior paws and hop three legged across the cage to deposit it also! E counted 239 tail and 81 paw retrievals during the retrieving tests alone; Ss were often observed engaging in these behaviors at other times. During the retrieving tests Ss carried their appendages over 1906 floor areas, a total distance of $953 \mathrm{ft}$. The retrieving tests so reliably triggered this behavior in some of the Ss that it was possible to obtain good photographic records.

Over $80 \%$ of the Ss were seen engaging in appendage retrieving over the course of the experiment although much of this behavior did not occur during retrieving tests proper and thus was not quantified. These behaviors may reflect a failure to discriminate appropriate objects for retrieval; post partum females may be acutely sensitive to moving objects. A decreased pain sensitivity may also be relevant. Ss sometimes retrieved their tails so many times that the skin became quite raw. In any case appendage retrieving appeared to be a common element in the maternal behavior of the rat under these experimental conditions. Certainly they could not be viewed as "abnormal" as might be implied in some of the literature (e.g. see discussion of Fisher's 1956 study in Money, 1965).

\section{References}

Beach, F. A., \& Jaynes, J. Studies of maternal retrieving in rats. I. Recognition of young. J. Mammal., 1956, 37, 177-180.

Eibl-Eibesfeldt, I. The interaction of unlearned behavior patterns and learning in mammals. In J. F. Delafresnaye (Ed.), Brain mechanisms and learning: A symposium. Springfield, Ill.: C. C. Thomas, 1961. Pp. 53-73.

Fisher, A. E. Maternal and sexual behavior induced by intracranial brain stimulants. Science, 1956, 124, 228-229.

Money, J. (Ed.) Sex research: New developments. New York: Holt, Rinehart and Winston, 1965.

Slotnick, B. M. Disturbances of maternal behavior in rats following lesions of the dorsal limbic cortex. Disser. Abst., 1963.

Wiesner, B. P., \& Sheard, N. M. Maternal behavior in the rat. Edinburgh: Oliver \& Boyd, 1933.

Wilsoncroft, W. E. Effects of median cortex lesions on the maternal behavior of the rat. Psychol. Rept., 1963, 13, 835-838.

\section{Note}

1. Paper presented at the WPA Convention, Hawaii, 1956. This research was supported by grant No. MH-5207 from NIMH and CHHD to Dr. O. T. Law. 